\title{
Global Solar Radiation Studies Due to Sunshine Hours and Other Meteorological Parameters
}

\author{
${ }^{1}$ Mfon David Umoh, ${ }^{2}$ Sunday O. Udo and ${ }^{3}$ Ye-Obong N. Udoakah \\ ${ }^{1}$ Department of Physics, Faculty of Science, \\ University of Uyo, Uyo Akwa Ibom State, Nigeria \\ ${ }^{2}$ Department of Physics, Faculty of Science, \\ University of Calabar, Calabar Cross River State, Nigeria \\ ${ }^{3}$ Department of Electrical/Electronics Engineering, \\ Faculty of Engineering, University of Uyo, Uyo Akwa Ibom State, Nigeria
}

Received 2013-08-07, Revised 2013-09-29; Accepted 2013-09-30

\begin{abstract}
Multiple linear regression models were developed to estimate the monthly daily Sunshine Hours using four parameters during a period of eleven years (1997-2007) for locations in South Eastern Nigeria. These locations include Uyo (Latitude $5^{\circ} 18^{\prime} 53.7^{\prime}$ 'N), Calabar (Latitude $5^{\circ} 16^{\prime} 07.6^{\prime}$ N), Port Harcourt (Latitude $4^{\circ} 56^{\prime} 26.2^{\prime \prime} \mathrm{N}$ ), Warri (Latitude $5^{\circ} 34^{\prime} 21.0^{\prime}{ }^{\prime} \mathrm{N}$ ), Enugu (Latitude $6^{\circ} 27^{\prime} 42.42^{\prime} \mathrm{N}$ ), Owerri (Latitude $\left.5^{\circ} 38^{\prime} 05.1^{\prime \prime} \mathrm{N}\right)$. The parameters include Relative Humidity, Maximum and Minimum temperatures, Rainfall and Wind Speed. The result of the correlations show that four variable correlations with the highest value of $\mathrm{R}$ for each of the six locations give the best result when considering the error term (RMSE). The models are Uyo $(\mathrm{S}=-16.876-2.065 \mathrm{RF}+0.237 \mathrm{~W}+1.278 \mathrm{~T}+0.129 \mathrm{RH})$, Calabar $(\mathrm{S}=-11.049-6.540 \mathrm{RF}-$ $0.534 \mathrm{~W}+0.142 \mathrm{RH}+1.127 \mathrm{~T})$, Portharcourt $(\mathrm{S}=-27.306+0.270 \mathrm{RH}+1.806 \mathrm{~T}-0.281 \mathrm{RH}-1.114 \mathrm{~W})$, erri $(\mathrm{S}=$ $0.677+9.776 \mathrm{RF}-0.689 \mathrm{~W}-0.057 \mathrm{RH}+0.900 \mathrm{~T})$, Enugu $(\mathrm{S}=10.279+5.519 \mathrm{RF}-0.586 \mathrm{~W}-0.079 \mathrm{RH}+0.217 \mathrm{~T})$, Warri $(\mathrm{S}=-22.424+0.272 \mathrm{RH}+1.388 \mathrm{~T}-9.791 \mathrm{RF}-0.623 \mathrm{~W})$. But when considering average values for the six locations, the correlation gives ( $\mathrm{S}=15.395+0.159 \mathrm{RH}-0.131 \mathrm{~T}+0.714 \mathrm{RF}+0.187 \mathrm{~W}$ ). Where $\mathrm{RH}$ is Relative humidity, $\mathrm{T}$ is the Difference in maximum and minimum temperature, $\mathrm{RF}$ is RainFall and $\mathrm{W}$ is wind speed. The developed models can be used in estimating Global solar radiation for the six locations under study. It can also be used to estimate Global solar radiation for other places in South Eastern Nigeria where only sunshine records are available.
\end{abstract}

Keywords: Global Solar Radiation, Sunshine Hours

\section{INTRODUCTION}

Sunshine duration is one of the most widely measured and applied meteorological parameters. This is because it plays a very major role in the determination of global solar radiation data. Solar radiation has temporal and spatial variations. To collect this information, a network of solar monitoring stations equipped with pyranometers and data acquisition systems are generally established in the desired locations. However, the number of such stations in the network is usually not sufficient to provide solar radiation data of the desired areas, especially in developing countries. This is mainly due to their inability to afford the measuring equipment and lack of technical competency. Therefore, it is necessary to develop methods to estimate the solar radiation on the basis of the more readily available meteorological data (Ahmed and Hussein, 2012). In developing countries such as Nigeria, it has been very difficult measuring global solar radiation due to the none Corresponding Author: $\begin{aligned} & \text { Mfon David Umoh, Department of Physics, Faculty of Science, University of Uyo, Uyo Akwa Ibom State, } \\ & \text { Nigeria }\end{aligned}$ 
availability of equipment or none functioning of these equipments. Duration of sunshine has thus been used as an alternative way of estimating this parameter. Sunshine duration is not only easy to use at networks of stations, it is relatively reliable. It enables spatial interpolation thus filling in gaps left by missing or unavailable data. One of the earliest correlations was proposed as far back as 1924 by Angstrom and relates global solar radiation to hours of bright sunshine. Several empirical models have been developed to calculate global solar radiation using various parameters (Umoh and Udoh, 2010; Akpan and Umoh, 2011a; 2011b; Khan and Ahmad, 2012; Ahmed and Hussein, 2012; Jakhrani et al., 2013; Kaya, 2012; Al-Dulaimy et al., 2010). The parameter used as input in the calculations include, sunshine duration, Mean temperature, soil temperature, relative humidity, number of rainy days, altitude, latitude, total perceptible water, albedo, atmospheric pressure, cloudiness and evaporation. The most commonly used parameter for estimating global solar radiation is sunshine hours which can be easily and reliably measured and data are widely available.

In this article, we develop equations that correlate monthly average daily sunshine hours with certain meteorological parameters for six locations in South Eastern Nigeria. The applicability of the models is also examined.

\section{MATERIALS AND METHODS}

Monthly average Sunshine hours, Relative Humidity, Maximum and Minimum Temperatures, Rainfall data and Wind speed data were obtained from the Nigerian Meteorological Agency (NIMET) in Oshodi, Lagos. The data covered a period of eleven years (1997 to 2007). The study covers six locations in the South Eastern part of Nigeria. This include: Uyo (Latitude $\quad 5^{\circ} 18^{\prime} 53.7^{\prime}$ N), Calabar (Latitude
5'16'07.6'’ N), Port Harcourt (Latitude 456’26.2'’ N), Warri (Latitude 5 $5^{\circ} 4^{\prime} 21.0^{\prime}$ 'N), Enugu (Latitude $6^{\circ} 27^{\prime} 42.42^{\prime}$ 'N), Owerri (Latitude 5'38'05.1'’ N). Monthly averages for the six locations under study (over the eleven year period) of the data in preparation for correlation are presented in Table 1.

Multiple Linear regression equation for estimating $\mathrm{S}$ with four parameters is as follows:

$$
\mathrm{Y}=\mathrm{a}+\mathrm{bX} \mathrm{X}_{1}+\mathrm{CX}_{2}+\mathrm{dX}_{3}+\mathrm{eX}_{4}
$$

where, a.....e, are the regression coefficients and $\mathrm{X}_{\mathrm{i}}$ is the correlated parameter. The estimated values were compared to measured values in each regression equation through correlation coefficient $\mathrm{R}$ and standard error of estimate $\sigma$.

\subsection{Correlations}

The various meteorological parameters shown in Table 1 are all related to sunshine hours in varying degrees. In order not to overlook any particular parameter or group of parameters, multiple linear regressions of four parameters ( $\mathrm{RH}, \mathrm{T}, \mathrm{RF}$ and $\mathrm{W}$ ) were employed to estimate the sunshine hours. Here $\mathrm{S}$ is the monthly average daily Sunshine hours, $\mathrm{RH}$ is the monthly average daily Relative Humidity in percentage, $\mathrm{RF}$ is the monthly average daily rainfall in millimeters, $\mathrm{W}$ is the monthly average daily Wind speed in $\mathrm{m} / \mathrm{s}$.

The various linear regression analyses are as follows.

\subsection{One Variable Correlation}

This correlation gives the highest value of $\mathrm{R}$ as 0.753 for $\mathrm{RH}$ and lowest value of $\mathrm{R}$ as 0.188 for $\mathrm{W}$ :

$$
\begin{aligned}
& \mathrm{S}=11.278-0.101 \mathrm{RH}(\mathrm{R}=0.753, \sigma=0.99362) \\
& \mathrm{S}=7.134-0.0723 \mathrm{~W}(\mathrm{R}=0.188, \sigma=0.148270)
\end{aligned}
$$

Table 1. Monthly average Sunshine hours and relevant meteorological parameters data for the six locations

\begin{tabular}{lllrrr}
\hline Month & $\mathrm{S}, \mathrm{hrs}$ & $\mathrm{RH}(\%)$ & $\mathrm{T},{ }^{\circ} \mathrm{C}$ & $\mathrm{RF}, \mathrm{mm}$ & $\mathrm{W}, \mathrm{m} / \mathrm{s}$ \\
\hline Jan. & 7.70 & 50.90 & 10.90 & 31.00 & 3.80 \\
Feb. & 4.80 & 52.10 & 20.10 & 51.00 & 4.00 \\
Mar. & 4.40 & 61.00 & 9.50 & 138.00 & 3.80 \\
Apr. & 4.50 & 67.50 & 15.80 & 267.00 & 3.50 \\
May & 4.90 & 72.70 & 7.20 & 279.00 & 3.90 \\
Jun. & 3.90 & 74.80 & 7.00 & 632.00 & 3.30 \\
Jul. & 4.90 & 77.00 & 6.50 & 352.00 & 3.70 \\
Aug. & 1.80 & 79.30 & 6.70 & 367.00 & 3.90 \\
Sep. & 2.90 & 78.40 & 6.90 & 249.00 & 3.80 \\
Oct. & 4.00 & 74.60 & 8.00 & 84.00 & 3.30 \\
Nov. & 5.20 & 60.80 & 8.90 & 15.00 & 3.10 \\
Dec. & 5.60 & 53.30 & 10.60 & & 2.80 \\
\hline
\end{tabular}




\subsection{Two Variable Correlation}

This correlation gives the highest value of $\mathrm{R}$ as 0.795 for $\mathrm{RH}$ and $\mathrm{T}$ and lowest value of $\mathrm{R}$ as 0.755 for $\mathrm{RH}$ and $\mathrm{W}$ :

$$
\begin{aligned}
& S=14.450-0.131 \mathrm{RH}-0.118 \mathrm{~T} \\
& (\mathrm{R}=0.795, \sigma=0.96460) \\
& \mathrm{S}=12.011-0.099 \mathrm{RH}-0.231 \mathrm{~W} \\
& (\mathrm{R}=0.755, \sigma=1.04313)
\end{aligned}
$$

\subsection{Three Variable Correlation}

This correlation gives the highest value of $\mathrm{R}$ as 0.803 for RH, T and RF and lowest value of R as 0.596 for $\mathrm{T}$, $\mathrm{RF}$ and $\mathrm{W}$ :

$$
\begin{aligned}
& S=15.716-0.154 R H-0.0123 \mathrm{~T} \\
& +1.617 \mathrm{RF}(\mathrm{R}=0.803, \sigma=1.00554) \\
& \mathrm{S}=7.421+0.018 \mathrm{TW}-4.319 \mathrm{RF}-0.573 \mathrm{~W} \\
& (\mathrm{R}=0.596, \sigma=1.35552)
\end{aligned}
$$

\subsection{Four Variable Correlation}

$$
\begin{aligned}
& \mathrm{S}=15.395-0.159 \mathrm{RH}-0.131 \mathrm{~T}+1.7144 \mathrm{RF} \\
& +0.187 \mathrm{~W}(\mathrm{R}=0.804, \sigma=1.0719)
\end{aligned}
$$

\section{RESULTS}

Equation (1), (3), (5), (7) have the highest value of correlation coefficient while Equation (2), (4) and (6) have the lowest values of $R$. However, the applicability of the proposed correlations is tested by estimating the sunshine duration values for the six locations representing the South eastern Nigeria used in the analysis. Estimated (average) values of sunshine duration for the six locations under study along with the measured data are shown in Table 2. Inspection of the table shows that the models estimate sunshine hours fairly accurately.

The following observations can be made from a study of Table 3. Based on the RMSE, Equation (7) produces the best correlation while Equation (5) gives the worst with larger value of RMSE. For MBE the result shows that Equation (1), (6) and (7) is the best while Equation (5) is the worst. With respect to MPE, Equation (7) offers the best correlation while Equation (5) gives the worst.

For the error calculations, a low MBE is desired. Ideally a zero value of MBE should be obtained. A positive value gives the average amount of overestimation in the calculated value and vice versa. A drawback of this test is that over estimation of an individual observation will cancel under estimation in a separate observation. It is obvious that each test by itself may not be an adequate indicator of a model's performance. It is possible to have a large RMSE value and at the same time a small MBE (a large scatter about the line of perfect estimation). On the other hand, it is also possible to have a relatively small RMSE and a relatively large MBE (a consistently small over-or underestimation) (Khan and Ahmad, 2012).

Figure 1 shows plots of Equation (7) with the least value of RMSE together with the monthly average daily sunshine hours measured for eleven years. Equation (7) shows almost exact fit to the sunshine hours data.

Based on Equation 7, the values of global solar radiation $(\mathrm{H})$, were computed and presented in Table 7 .

Table 2. Estimated (average) values of sunshine duration for the six locations under study along with the measured data

\begin{tabular}{lllllllll}
\hline Month & $\mathrm{S}$ & Eq. 1 & Eq. 2 & Eq. 3 & Eq. 4 & Eq. 5 & Eq. 6 & Eq. 7 \\
\hline Jan. & 7.70 & 6.14 & 4.39 & 6.50 & 6.09 & 7.92 & 5.31 & 6.64 \\
Feb. & 4.80 & 6.02 & 4.24 & 5.25 & 5.39 & 7.53 & 5.27 & 5.31 \\
Mar. & 4.40 & 5.12 & 4.39 & 5.34 & 5.09 & 6.43 & 4.82 & 5.40 \\
Apr. & 4.50 & 4.46 & 4.60 & 3.74 & 4.52 & 5.57 & 4.51 & 3.72 \\
May & 4.90 & 3.39 & 4.31 & 4.08 & 3.91 & 4.88 & 4.11 & 4.10 \\
Jun. & 3.90 & 3.72 & 4.75 & 3.83 & 3.84 & 5.13 & 2.93 & 4.28 \\
Jul. & 4.90 & 3.50 & 4.46 & 3.60 & 3.53 & 4.35 & 3.90 & 3.59 \\
Aug. & 1.80 & 3.27 & 4.31 & 3.27 & 3.26 & 3.92 & 4.00 & 3.17 \\
Sep. & 2.90 & 3.36 & 4.39 & 3.37 & 3.37 & 4.15 & 3.78 & 3.37 \\
Oct. & 4.00 & 3.74 & 4.75 & 3.73 & 3.86 & 4.53 & 4.60 & 3.53 \\
Nov. & 5.20 & 5.14 & 4.89 & 5.44 & 5.28 & 638 & 5.44 & 5.29 \\
Dec. & 5.60 & 5.89 & 5.11 & 6.22 & 6.09 & 7.40 & 5.94 & 6.08 \\
\hline
\end{tabular}


Table 3. Error calculations

\begin{tabular}{lllrr}
\hline Equation & $\mathrm{R}$ & MBE & RMSE & MPE \\
\hline 1 & 0.7530 & -0.0258 & 0.9084 & 5.2917 \\
2 & 0.1880 & 0.0367 & 1.3889 & 13.6800 \\
3 & 0.7850 & 0.0142 & 0.8351 & 5.0033 \\
4 & 0.7500 & 0.0142 & 0.9048 & 6.0967 \\
5 & 0.8030 & 1.1325 & 1.4592 & 31.5417 \\
6 & 0.5960 & -0.0142 & 1.1446 & 8.6442 \\
7 & 0.8040 & -0.0100 & 0.8190 & 4.9842 \\
\hline
\end{tabular}

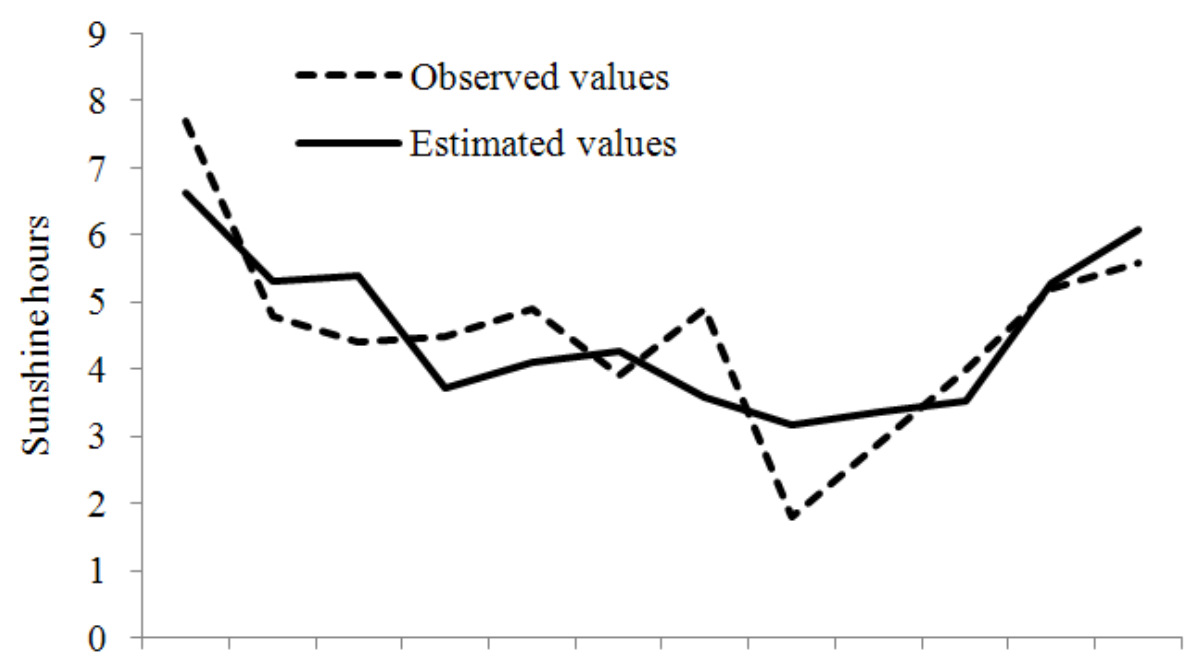

Jan. Feb. Mar. Apr. May Jun. Jul. Aug. Sep. Oct. Nov. Dec.

Month

Fig. 1. Comparison of measured and estimated data of monthly average daily sunshine hours for the six locations representing the south Eastern Nigeria

\section{DISCUSSION}

Measured values of Sunshine hours for the six locations under study; Uyo, Calabar, Enugu, Owerri, Port Harcourt and Warri are presented in Table 5. The Calculated values of the same variable for the six locations are also presented in Table 6. The values are compared with the average values representing South Eastern Nigeria. Inspection of Table 5 shows that there is not much disparity between the measured data for the six locations and the average data representing the South Eastern Nigeria. The has much effect on the data obtained in Table 6. Inspection of Table 6 indicates that the calculated values of Sunshine hours for the six locations are very close to the ones obtained for the South Eastern Nigeria. This invariably means that the calculated values obtained for the the South Eastern Nigeria can be used effectively to compute Global solar radiation for any of the six locations if the sunshine hours data for the location is not readily available. Table 4 and 7 shows the estimated values of global solar radiation for the six locations under study. A close examination of the Table 7 shows very close proximity of the global solar radiation data estimated for the six locations with the ones for the South eastern Nigeria. The values estimated for the South Eastern Nigeria can be used by scientist and engineers designing solar systems for the six locations under study. The comparison of global solar radiation data estimated for the six locations and for the South Eastern Nigeria is presented in Fig. 2. The figure also displays close proximity of the estimated data. Table 7 indicates that the greatest amount solar radation in the South Eastern part of Nigeria was obtained in January $\left(17.03 \mathrm{MJ} / \mathrm{m}^{2}\right)$ while the least value was obtained in August $\left(12.47 \mathrm{MJ} / \mathrm{m}^{2}\right)$. 


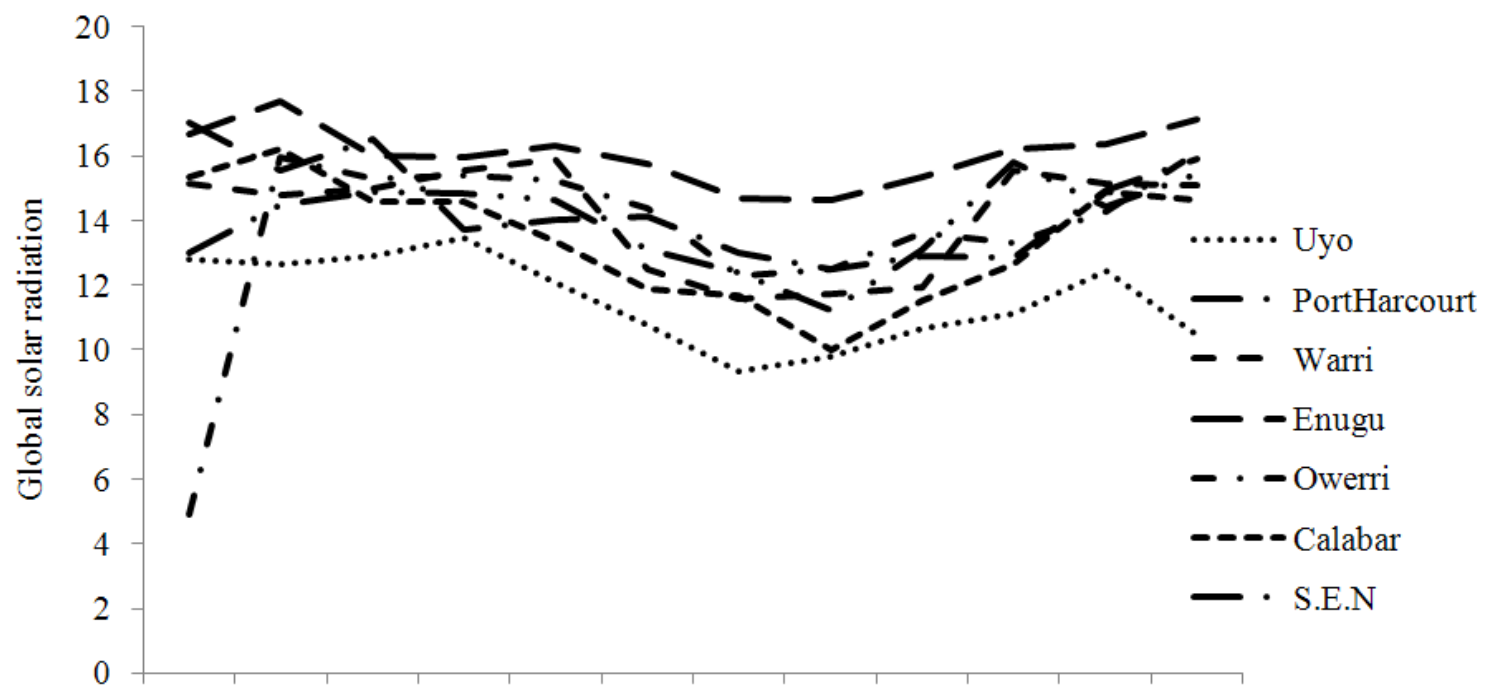

Jan. Feb. Mar. Apr. May Jun. Jul. Aug. Sep. Oct. Nov. Dec.

Month

Fig. 2. Comparison of Global solar radiation for the six locations and The South Eastern Nigeria (S.E.N)

Table 4. Values of Global solar radiation for the six locations representing the South Eastern Nigeria

\begin{tabular}{llllll}
\hline Month & $\mathrm{H}\left(\mathrm{MJ} / \mathrm{m}^{2}\right)$ & $\mathrm{H}_{\mathrm{o}}\left(\mathrm{MJ} / \mathrm{m}^{2}\right)$ & $\mathrm{S}(\mathrm{hrs})$ & $\mathrm{S}_{\mathrm{o}}(\mathrm{hrs})$ & $\mathrm{S} / \mathrm{S}_{\mathrm{o}}$ \\
\hline Jan. & 17.03 & 34.33 & 6.64 & 11.72 & 0.57 \\
Feb. & 15.53 & 36.28 & 5.31 & 11.83 & 0.45 \\
Mar. & 16.50 & 38.00 & 5.40 & 11.97 & 0.45 \\
Apr. & 13.69 & 38.71 & 3.72 & 12.13 & 0.31 \\
May & 14.03 & 38.34 & 4.10 & 12.25 & 0.33 \\
Jun. & 14.11 & 37.92 & 4.28 & 12.32 & 0.35 \\
Jul. & 13.00 & 38.09 & 3.59 & 12.29 & 0.29 \\
Aug & 12.47 & 38.65 & 3.17 & 12.18 & 0.26 \\
Sep. & 12.87 & 38.43 & 3.37 & 12.03 & 0.29 \\
Oct. & 12.83 & 36.94 & 3.53 & 11.87 & 0.30 \\
Nov. & 14.93 & 34.88 & 5.29 & 11.74 & 0.45 \\
Dec. & 15.91 & 33.74 & 6.08 & 11.68 & 0.52 \\
\hline
\end{tabular}

Table 5. Measured values of Sunshine hours (S) for the six locations and the South Eastern Nigeria

\begin{tabular}{llllllll}
\hline Month & Uyo & PortHarcourt & Warri & Enugu & Owerri & Calabar & S.E.N \\
\hline Jan. & 3.10 & 4.30 & 4.81 & 6.13 & 5.29 & 5.30 & 7.70 \\
Feb. & 3.61 & 4.24 & 4.60 & 6.32 & 5.45 & 4.66 & 4.80 \\
Mar. & 2.92 & 3.84 & 4.60 & 5.58 & 4.48 & 3.75 & 4.40 \\
Apr. & 3.15 & 4.41 & 4.92 & 6.05 & 4.84 & 4.06 & 4.50 \\
May & 3.40 & 4.85 & 4.90 & 6.32 & 5.85 & 4.28 & 4.90 \\
Jun. & 2.56 & 3.74 & 3.72 & 5.03 & 4.60 & 3.57 & 3.90 \\
Jul. & 1.47 & 2.28 & 2.27 & 3.67 & 3.12 & 2.52 & 4.90 \\
Aug. & 1.24 & 2.36 & 2.45 & 3.64 & 2.47 & 1.46 & 1.80 \\
Sep. & 1.99 & 3.30 & 2.48 & 4.28 & 3.19 & 2.31 & 2.90 \\
Oct. & 2.75 & 4.07 & 4.25 & 5.54 & 3.95 & 3.15 & 4.00 \\
Nov. & 3.35 & 5.08 & 5.68 & 6.98 & 5.34 & 4.72 & 5.20 \\
Dec. & 2.84 & 5.37 & 5.24 & 6.98 & 5.50 & 5.74 & 5.60 \\
\hline
\end{tabular}


Table 6. Calculated values of Sunshine hours (S) for the six locations and for The South Eastern Nigeria

\begin{tabular}{llllllll}
\hline Month & Uyo & PortHarcourt & Warri & Enugu & Owerri & Calabar & S.E.N \\
\hline Jan. & 3.62 & 3.83 & 5.25 & 6.59 & 5.38 & 5.26 & 6.64 \\
Feb. & 3.33 & 4.22 & 4.59 & 6.70 & 5.48 & 5.29 & 5.31 \\
Mar. & 3.22 & 4.09 & 4.41 & 5.25 & 4.80 & 4.19 & 5.40 \\
Apr. & 3.32 & 4.07 & 4.58 & 5.02 & 4.50 & 3.99 & 3.72 \\
May & 2.89 & 4.03 & 4.88 & 5.32 & 4.68 & 3.63 & 4.10 \\
Jun. & 2.26 & 3.37 & 3.20 & 5.06 & 4.36 & 2.80 & 4.28 \\
Jul. & 1.62 & 2.96 & 2.54 & 4.31 & 3.08 & 2.68 & 3.59 \\
Aug. & 1.73 & 2.35 & 2.57 & 4.24 & 3.14 & 3.79 & 3.17 \\
Sep. & 2.20 & 3.16 & 2.62 & 4.67 & 3.74 & 2.51 & 3.37 \\
Oct. & 2.52 & 4.75 & 4.88 & 5.73 & 3.88 & 3.36 & 3.53 \\
Nov. & 3.44 & 4.43 & 5.12 & 6.33 & 4.87 & 4.84 & 5.29 \\
Dec. & 2.61 & 5.18 & 5.39 & 7.16 & 6.26 & 5.00 & 6.08 \\
\hline
\end{tabular}

Table 7. Calculated values of global solar radiation $(\mathrm{H})$ for the six locations and The South Eastern Nigeria

\begin{tabular}{llllllll}
\hline Month & Uyo & PortHarcourt & Warri & Enugu & Owerri & Calabar & S.E.N \\
\hline Jan. & 12.79 & 12.99 & 15.10 & 16.64 & 14.89 & 15.36 & 17.03 \\
Feb. & 12.64 & 14.47 & 14.77 & 17.66 & 15.96 & 16.22 & 15.53 \\
Mar. & 12.91 & 14.85 & 14.98 & 16.01 & 15.31 & 14.61 & 16.50 \\
Apr. & 13.45 & 14.80 & 15.52 & 15.95 & 15.37 & 14.58 & 13.69 \\
May & 12.08 & 14.62 & 15.88 & 16.31 & 15.23 & 13.36 & 14.03 \\
Jun. & 10.75 & 13.10 & 12.50 & 15.73 & 14.36 & 11.91 & 14.11 \\
Jul. & 9.31 & 12.36 & 11.56 & 14.68 & 12.30 & 11.71 & 13.00 \\
Aug. & 9.75 & 11.21 & 11.72 & 14.62 & 12.47 & 10.02 & 12.47 \\
Sep. & 10.62 & 13.08 & 11.92 & 15.34 & 13.58 & 11.57 & 12.87 \\
Oct. & 11.10 & 15.79 & 15.53 & 16.20 & 13.29 & 12.67 & 12.83 \\
Nov. & 12.43 & 14.44 & 15.12 & 16.33 & 14.26 & 14.88 & 14.93 \\
Dec. & 10.42 & 15.45 & 15.06 & 17.11 & 16.10 & 14.62 & 15.91 \\
\hline Wh & & & & & &
\end{tabular}

Where S.E.N represents South Eastern Nigeria

\subsection{Computation of Global Solar Radiation}

There are several formulae that relate global radiation to other climatological parameters such as sunshine hours, relative humidity, maximum temperature and average temperature. The first correlation proposed for estimating the monthly average daily global irradiation is due to Angstrom. The original Angstrom-type regression equation related monthly average daily radiation to clear day radiation at the location in the question and average fraction of possible sunshine hours:

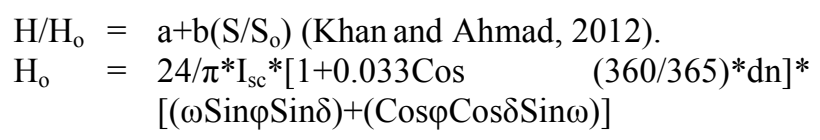

And:

$\mathrm{W}=\operatorname{Cos}^{-1}(-\tan \delta \tan \varphi)$

$\mathrm{S}_{\mathrm{o}}=(2 / 15) \omega$

\section{CONCLUSION}

Multiple regressions have been employed in this study to develop several correlation equations used to describe the dependence of sunshine hours on other meteorological data for six locations and the South Eastern part of Nigeria. The result shows that the four variable correlations which is the equation with the highest $\mathrm{R}$ give the best result when considering the error term (RMSE). Hence the multiple regression equation that could be employed for the purpose of estimating sunshine hours of locations that have the same climate and latitude as the six locations under study.

The equation with the least value of RMSE is:

$$
\mathrm{S}=15.395-0.159 \mathrm{RH}-0.131 \mathrm{~T}+1.7144 \mathrm{RF}+0.187 \mathrm{~W}
$$

Based on Table 7, the greatest amount of global solar radiation was received in January $\left(17.03 \mathrm{MJ} / \mathrm{m}^{2}\right)$ and the least amount of global solar radiation was received in August $\left(12.47 \mathrm{MJ} / \mathrm{m}^{2}\right)$. 


\section{ACKNOWLEDGEMENT}

The reacheres are grateful to the Nigeria meteorological Agency (NIMET), Oshodi, Lagos for providing all the necessary data.

\section{REFERENCES}

Ahmed, T. and T. Hussein, 2012. Estimation of hourly global solar radiation in Egypt using mathematical model. Int. J. Latest Trends Agric. Food Sci., 2: 7482.

Akpan, U.E. and M.D. Umoh, 2011a. Horizontal global solar radiation based on sunshine hours over Enugu, Nigeria. Canad. J. Pure Applied Sci., 5: 1553-1557.

Akpan, U.E. and M.D. Umoh, 2011b. Estimating global solar radiation from sunshine hours for Uyo, Nigeria. Canad. J. Pure Applied Sci., 5: 1433-1437.
Al-Dulaimy, F.M. and G.Y.M. Al-Shahery, 2010. Estimation of Global Solar Radiation on Horizontal Surfaces over Haditha Samara and Beji, Iraq. Pacific J. Sci. Technol., 11: 73-82.

Jakhrani, A., S. Samo, A. Rigit and S. Kamboh, 2013. Selection of models for calculation of incident solar radiation on tilted surfaces. World Applied Sci. J., 22: 1334-1343.

Kaya, M., 2012. Estimation of global solar radiation on horizontal surface in Erzincan, Turkey. Int. J. Phys. Sci., 7: 5273-5280. DOI: 10.5897/IJPS12.351,

Khan, M. and M.J. Ahmad, 2012. Estimation of global solar radiation using clear sky radiation in Yemen. Int. Res. J. Eng. Sci. Technol. Innov., 1: 228-237.

Umoh, M. and S. Udoh, 2010. Estimation of global solar radiation from sunshine hours for Warri, Nigeria. Global J. Environ. Sci., 9: 51-56. 